\title{
L-3-(3-CARBOXYFURAN-4-YL)ALANINE, A NEW AMINO ACID FROM THE MUSHROOM PHYLLOTOPSIS NIDULANS*
}

\author{
RICHARD R. DOYLE† and BRUCE LEVENBERG $\dagger$ \\ Department of Biological Chemistry, The Ciniversity of Michigan, Ann Arbor, Michigan 48104, US A
}

(Recelved 7 Aprol 1974)

Key Word Index - Phyllotopsis nldulans, Basidiomycetes, fungı, furan, amıno acid

\begin{abstract}
A ncw amino acid has been discovered in uncombined form in extracts of the fruiting bodies of the mushroom, Phyllotopsis nidulans Chemical and spectroscopic data support formulation of the structure as L-3-(3carboxyfuran-4-yl)alanıne
\end{abstract}

INTRODUCTION

BASIDIOCARP extracts of the mushroom, Phyllotopsis nidulans (Pers. ex Fr.) Sing. were examined during the course of a search for new amino acids in higher fungi. ${ }^{1,2} 2 \mathrm{D}$ PC revealed the presence of an unusual ninhydrin-positive compound which absorbed in UV light. This paper describes its identıfication as L-3-(3-carboxyfuran-4-yl)alanine (1).

\section{RESULTS AND DISCUSSION}

Initial studies with partially purified solutions using small ion-exchange columns ind1cated that the new amino acid had an excess of acidic functional groups. Comparison of the UV spectra of these solutions with those of model compounds led to the conclusion that a furan ring was involved. Purification of the amino acid by ion-exchange and PC techniques yielded a crystalline substance, $\mathrm{C}_{8} \mathrm{H}_{9} \mathrm{NO}_{5}$ (FW 199.2) This formula was supported by the fact that a Chemical Ionization Mass Spectrum gave a parent peak at $m / e=$ 200. From this, it was formulated as a furanylalanine with an extra carboxyl group on the furan ring. Final resolution of the structure was bascd on the NMR spectrum of the dimethyl ester hydrochloride in $\mathrm{D}_{2} \mathrm{O}$ solution Besides confirming the presence of the alanıne side chain, this spectrum permitted assigning the carboxyl group and the $\beta$-alanyl side chain to the 3 and 4 positions, respectively, of the furan ring. Comparison of the pattern of furan ring proton signals with those of model furan derivatives showed that the

\footnotetext{
* Presented in part before the 51st Annual Meeting of the Federation of American Societies for Experimental Biology, Chicago, III, 18, April 1967 The investigation was supported by a grant (GM-13325) from the U S Public Health Service

+ Recipient of a postdoctoral fellowship (5-F2-CA-30,540) from the US Public Health Service Present Address Department of Chemıstry, Denıson Unıversity, Granvile, Ohı 43023 To whom reprint requests should be addressed

$\ddagger$ Deceased

${ }^{1}$ Levenberg, B (1968) J Biol Chem 243, 6009

2 Doyle, R R and Levenberg, B (1968) Biochem 7, 2457
} 
protons are present at positions 2 and 5 of the furan ring in the new amino acid The optical rotation was not measured because of the small amount of purified material avarlable, but the ammo acid was shoun to belong to the $\mathrm{L}$ series by chemical degradation to $\mathrm{L}-$ aspartic acid The latter product was determined encymatically by the MDH-GOT method ${ }^{3}$ and confirmed by its elution position on the ammo acid analyzer

\section{F XPERIMENTAL}

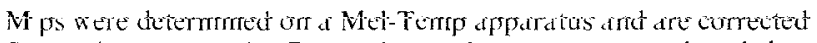

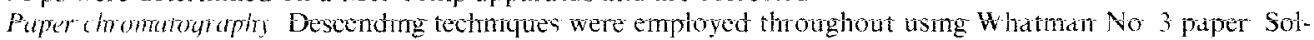
चक्ष

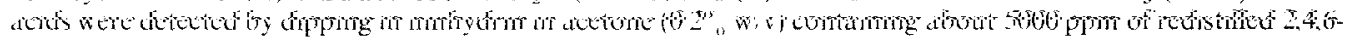

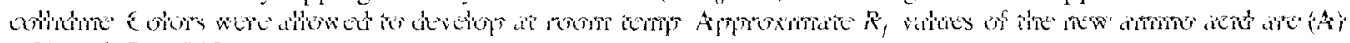
030 and (B) 0045

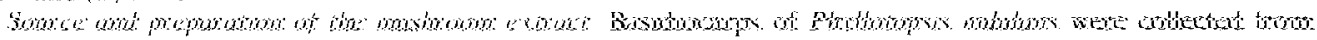

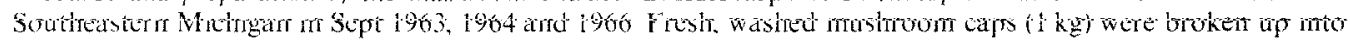

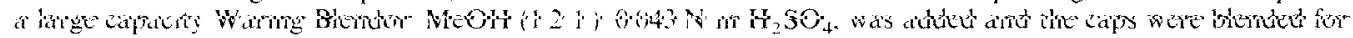

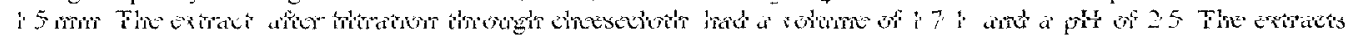

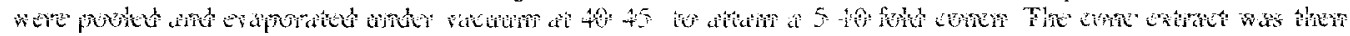
stored at -17 until necded

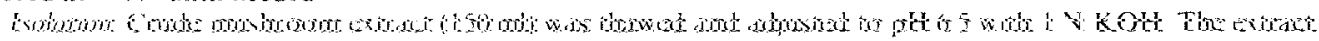

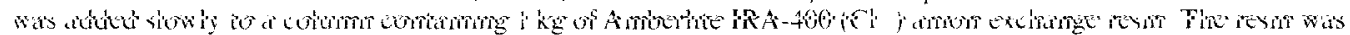

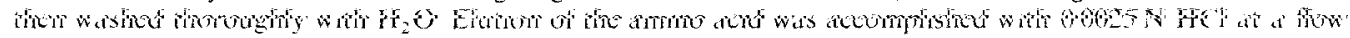

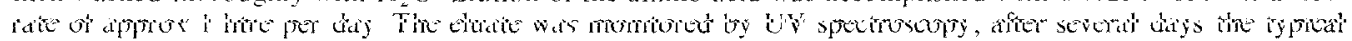

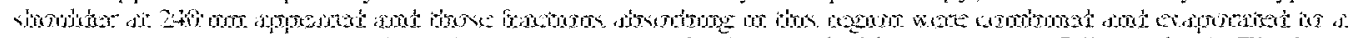

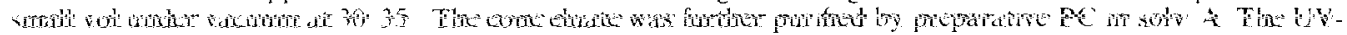

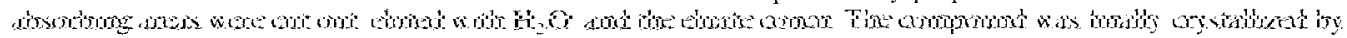
the addition of acetone

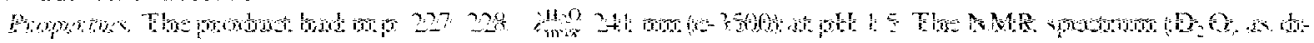

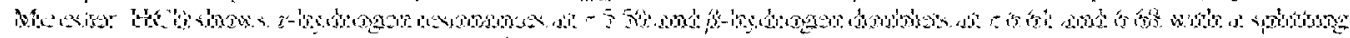

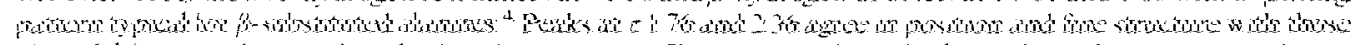

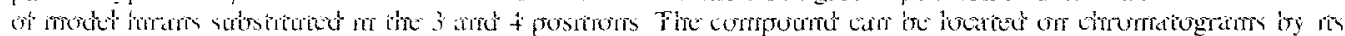

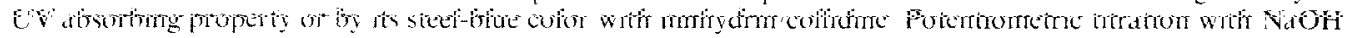

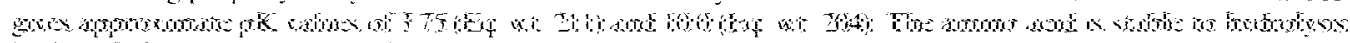

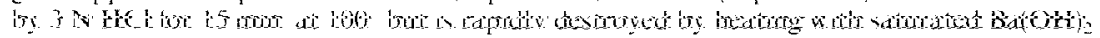

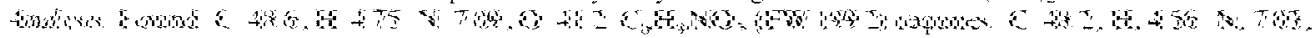

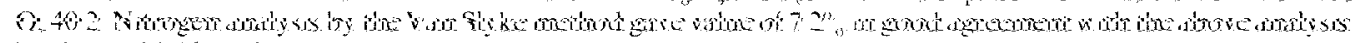
by the Kleldahl method

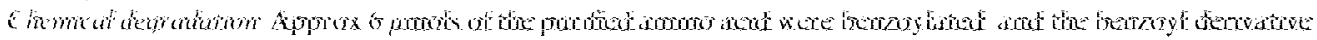

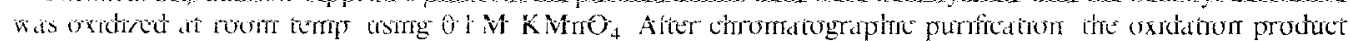

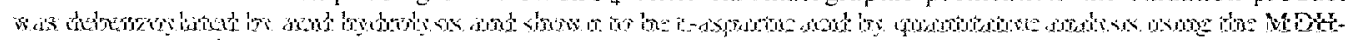
GOT procedure ${ }^{\text {i }}$

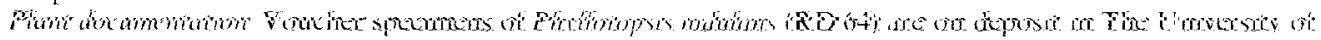
Michigan Herbarum. Dr Robert L Shaffer, curator

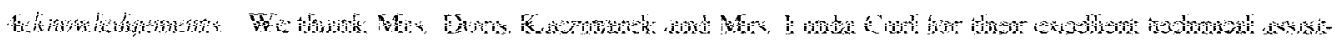

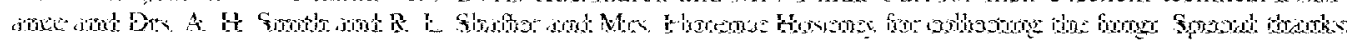

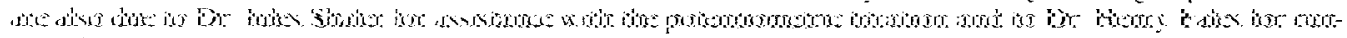

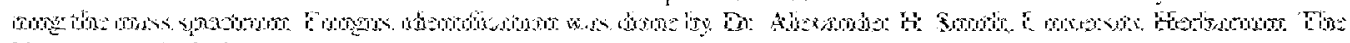
Iniversits of Michlean

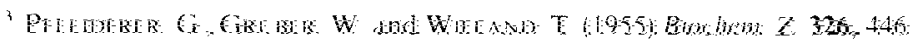

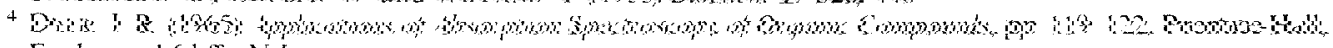
Englew ood C liffi $\mathrm{N} J$
} 